\title{
LIBRARIANS USE OF WEB 2.0 IN UK MEDICAL SCHOOLS: OUTCOMES OF A NATIONAL SURVEY
}

\author{
JENNY PACHECO \\ Academic Services Quality and Development Team, University Library, \\ University of Sheffield, Sheffield, UK \\ ISLA KUHN \\ University of Cambridge Medical Library, Addenbrooke's Hospital, \\ Cambridge, UK \\ VICKY GRANT \\ University of Sheffield, Health Sciences Library, Royal Hallamshire Hospital, \\ Sheffield, UK
}

\begin{abstract}
Address correspondence to Vicky Grant, Faculty Librarian for Medicine, Dentistry and Health, University of Sheffield, Health Sciences Library, Royal Hallamshire Hospital, Sheffield, S10 2JF, UK. E-mail: V.grant@sheffield.ac.uk
\end{abstract}

\begin{abstract}
Using the results of an Email survey, this paper reviews the use of Web 2.0 technologies by librarians working in UK Medical Schools. Web 2.0 has been hailed as an innovation for facilitation of two way communication on the net, and it is, therefore, timely to measure how effectively librarians are capturing this opportunity for increased student engagement. The social nature of Web 2.0 can be particularly appropriate for undergraduate medical students who fit their studies around the unsocial hours and geographical isolation of clinical placements. This paper will investigate library use of blogs, Facebook, and Twitter. Consideration will also be given as to whether they facilitate a more collabroative library service or if they leave undergraduate medical students swamped with yet more information to manage.
\end{abstract}

\section{Introduction}

The innovation of Web 2.0 has radically redefined the World Wide Web by facilitating two-way communication through social networking sites such as Facebook, Twitter, and blogs. Sodt and Summey (2009) succinctly described the advantages of this, stating that "Web 2.0 takes the stagnant Web 1.0 and makes it more user-driven, collaborative, participatory, and personalized" (97). This study measures how effectively librarians are capturing this opportunity for increased student engagement. Using the results of an Email survey this paper will describe how UKMedical School Librarians are using blogs, Facebook, and Twitter. Consideration will be given as to whether these are providing engaging new opportunities

for library service delivery or if they are merely leaving medical students swamped with yet more information to manage. A recent report on the use of Web 2.0 social software technologies in UK higher education maintains that "the educator's role is changing from being a provider of information to a facilitator or moderator" (Minocha, 2009 9). By introducing problem based learning into the curriculum, many UK medical schools have been forerunners in this change. Listed among the generic skills required for problem based learning is critical evaluation of the literature (Wood, 2003). It is cause for concern that a recent report (Committee of Inquiry into the Changing Learner Experience, 2009) states that information literacy (defined as searching, retrieving, critically evaluating, and attributing information) represents "a significant and growing deficit area" (6). This, coupled with the drive to support evidence based medicine has found 
many medical librarians becoming involved in the teaching of information literacy. Some key questions are emerging:

How are medical librarians using Web 2.0 technologies to complement this and to improve service provision?

_ Is Web 2.0 making libraries more student driven by creating an environment for increased two-way communication?

Are librarians successfully exploiting the social nature of Web

2.0 to engage medical students during their periods of clinical placement?

The potential for Web 2.0 in the education and training

of the clinician has been acknowledged by Kamel Boulos and

Wheeler (2007): "Web 2.0 encourages a more human approach

to interactivity on the web ... students can feel socially isolated if

they are geographically separated or studying during unsociable

hours" (3).

A blog, or weblog, is a diary format web application which

typically displays posts in chronological order. Sauers (2006) has

observed that librarians enjoy using blogs. Farkas (2008) explains

that "libraries have websites whose content hasn't changed in

months (or even years) . . . often the librarians aren't happy with

the current web presence but feel powerless to fix things" (45).

Using software such as Wordpress, a blog enables all library staff

members to easily add and update content, giving a more immediate

and current feel to eLibrary provision.

Initially started as a Web site for students at Harvard University,

Facebook (www.Facebook.com ) has fast become a global phenomenon

and is the most popular of all social networking sites.

Use of Facebook is free and users create their own page, or profile, giving personal and educational information about themselves.

All users have a wall where information, messages, photographs, and video clips can be posted.

Twitter (www.Twitter.com) is a Web 2.0 service which allows users to post short messages, known as tweets, from a computer or web-enabled phone. In no more than 140 characters, tweets were originally designed to respond to the question "what are you doing?" (Rushe, 2009). This has quickly evolved and users now also tend to use it as a "micro blogging" service, tweeting their current thoughts, feelings, and other information. Users are both followed by and are followers of other users. By following someone a user will be posted with their tweets (updates).

\section{Methodology}

A small study was undertaken to explore various aspects of Web

2.0 and UK university medical libraries with the intentions to:

_ Identify which academic health libraries were using some of

the most high profile Web 2.0 facilities-blogs, Facebook, and

Twitter

_ Establish how they were being used for 2-way communication

- Detail other Web 2.0 applications apart from those being used

to communicate with undergraduate medical students; what

means were being used instead

A short survey was developed using Survey Monkey

(www.surveymonkey.com) and Emailed to 31 UK university medical 
libraries. Two successive reminders were sent out, resulting in 20 contributions. Follow up interviews were carried out with 5 of the respondents.

\section{Results}

Blogs

Out of 20 libraries who responded to the survey, 6 have blogs, 4 of which were specifically directed at medical students. Different practices in these 4 sites are described in the following section.

CAMBRIDGE UNIVERSITY MEDICAL LIBRARY BLOG

HTTP://CAMBRIDGEMEDICALLIBRARY.BLOGSPOT.COM/

The Cambridge University Medical Library blog, entitled

"Medical Library" is kept by the Reader Services Librarian, and the Collection Development Librarian for users of the Medical Library. The blog is hosted by the blogging service "Blogger," and uses a standard blogger template for its look and feel. There is no information about the blog, but it has archives going back to December 2006. While posts are not tagged or categorized, older posts are available from the archive. The blogroll provides links to the Library website, as well as a few external sites of interest to the subject. Posts are wide ranging, and cover customer service information such as opening hours, ejournal access, and library training sessions, as well as in-depth subject specific information about relevant web resources, information on news stories, best practice information, and clinical information. New posts are made regularly, ranging from once a week to once a fortnight. The blog has garnered a few comments, but these are few and far between, so two-way communication is not currently achieved through the blog.

SWANSEa School of Health SCience blog HTTP://SUSHSLIBRARY.WORDPRESS.COM/

Swansea University's School of Health Science Library keeps a blog for its students, entitled "Swansea School of Health Science Library blog," which is posted to anonymously by "sushslibrary." The blog is hosted by the blogging service "Wordpress," and uses the default wordpress template for its look and feel. There is no information

about the blog or its contributors. It has archives going back to August 2008. All posts are categorized, so readers can view all posts on a particular topic on the blog, and they are also tagged so that readers can link through to posts from other blogs on the same topic. There is no blogroll providing links to other websites; however, Real Simple Syndication (RSS) feeds from relevant sites are included. Posts are varied, and again cover customer services information such as opening hours, inter-library loans, but also include advice on study skills, relevant web resources, government reports, health news stories, and video clips and radio reports. New posts are made with varying regularity, starting off weekly, but more recently fortnightly or monthly. So far the blog has not received any comments, and so is not yet effectively achieving two way communication with the students.

HULL YORK MEDICAL SCHOOL BLOG HTTP://HYMSLIBRARY.BLOGSPOT.COM/

Hull York Medical School Library keeps a blog for its students, entitled "News: News from HYMS Library services," which 
is posted to by "library@hyms.ac.uk." The blog is hosted by the blogging service "blogger," and uses a standard blogger template. There is no information about the blog or its contributors, but contact details for the library are given. It has archives going back to August 2008. Posts are not tagged or categorized, but older posts are available from the archive. There is no blogroll providing links to other websites. Posts are all customer services based, covering opening hours, database trials, ejournal access, advertising library surveys, and other topics of this nature. New posts are made weekly. There is no facility for readers to comment on the blog, or leave any feedback, and so naturally the blog is not creating any two way communication with students. This is intentional, as the Library runs the blog as a "'news' page only."

THE UNIVERSITY OF SHEFFIELD BLOG

HTTP://WWW.LIBRARYDEVELOPMENT.GROUP.SHEF.AC.UK/BLOGS/MED DENT/

The University of Sheffield's Faculty Librarian keeps the blog, entitled "Librarians' Blog forMedicine, Dentistry, and Health" for students in the Medical Faculty. The blog is a custom Wordpress installation on a University of Sheffield server and, as such, has been highly customized in its look and feel to represent the University Library, including original artwork to give it a distinctive and recognizable look and provide an image that can be used promotionally. It has additional pages about the blog and its contributors, and archives going back to January 2008. All posts are tagged with keywords which are listed in a tag cloud so that readers can see all posts on a particular topic, and it is also categorized depending on the discipline at which they are primarily aimed. The blogroll provides links to useful Library resources, as well as external sites of interest to the subject, and the University Library Twitter stream.

Posts are varied and cover both customer services information on opening hours and study spaces for revision, as well as subject specific information such as a regular "10 of the best" feature that introduces students to key medical resources online. New posts are made reasonably regularly, ranging from once a week to once a month depending on the time of year. There was little in the way of two way communication until a competition was run allowing all students who commented on the blog the chance to win an iPod. This generated a lot of interest and comments, but these have now tailed off again. However, the comments during the competition indicated that students do read the blog even though they are normally unwilling to leave a comment, and the librarian has found that while students do not often leave comments on the blog, each new post does generate Email enquiries to her inbox.

It was apparent from this survey that out of the three Web 2.0 tools considered, blogging appears to be where information literacy is best supported. Posts are commonly made promoting new information services and providing guidance on search techniques and the skills required for evidence based medicine. Library blogs also seem to be popular with students. One respondent said: "There was an eLearning questionnaire for the Faculty of 
Medicine students and they rated blogs highly and the usage stats [of the library blog] are high."

Where blogs are used, the communication is primarily of a

"push" nature-comments back being rare, unless invited, or encouraged with incentives. The following student comment on the

University of Sheffield blog suggests that such incentives can be used to generate genuine student interest: "Thanks so much for posting this blog! To be completely honest I really only came to this website for entirely selfish reasons, an i-pod:-) . . . [however] as a med student on GP

placement at the moment, I felt that I'd just been thrown a life-line. This resource really is invaluable for med students. Thanks again and I await with enthusiasm for future blogs!".

Other comments on the same blog have been used to influence library provision and there is some evidence that Web 2.0 can be used to "review students contributions and steer the educational process accordingly," (Minocha, 2009). Two blogs were of a more general nature, contributed to by several members of the library team. There was one instance of the librarian being aware that blogs were used as part of a particular course, for students to upload work, or to comment on each others work, but this was considered to be of mixed success since it appeared the students felt uncomfortable commenting on each others work in a public forum.

Facebook

The results from this study correspond to those from a similar discussion of health sciences libraries use of Facebook in the US (Hendrix et al., 2009). The use of Facebook by medical school librarians is still evolving and where it is used, it is directed at all students, not focusing only on medical students. The four Facebook groups identified in the study were generic for all students. They were also seen generally as experimental. The typical approach taken at one university library is described in the following section. DURHAM UNIVERSITY LIBRARY FACEBOOK PAGE

In common with the other library Facebook pages identified by our research, Durham University Library uses its wall area to post information about library opening hours, new books, and other customer service style announcements. Links are available to allow the search of catalogs such as Copac and WorldCat (a widget to allow the search of Durham's catalog will be added in due course) and to services such as online book renewals. This is very similar to how other libraries use their Facebook pages; for example, the University of Warwick Library (www.Facebook.com/pages/Coventry-UnitedKingdom/University-Of-Warwick-Library/616816250) also provides access to subject guides and some video clips on topics such as how to search the library catalog.

Although it contains a lot of the same information, Durham University Library's Facebook site aims to complement rather than replace the official library homepage. It highlights the most useful and popular services, and even gives information that was not strictly "library" information (e.g., about printer credits, 
which are controlled by the computing service). It was specifically set up with the aim of engaging in a less formal dialogue with "fans" than might otherwise be possible. The discussion board (available in the "boxes" area of the site) has suggested two topics-"your library questions" and "What do we do well? What can we do better? What aren't we doing?" As membership of the site has grown, so has the amount of engagement and discussion. Replies are given in direct response to the questions and issues raised and are available for all to see. News items are added by hand, rather than using an RSS feed from the library's website, specifically to ensure it felt like a person was involved.

Set up in January 2009, membership has grown quickly (307 fans at time of press) and without the aid of a major publicity campaign. A link has been placed on the library catalog (http://library.dur.ac.uk/), and the fact that it is available has been raised at staff-student consultative committees, but there is no aggressive targeting of students, and the uptake seems to have grown of it's own accord-exactly as the creator had hoped. Development of the site will be reviewed over the summer of 2009 in anticipation of the new intake of students, and the profile of the site is likely to be raised in order to make students more aware of library services.

Two-way communication does still seem to be a rarity, though, despite the inclusion of discussion boards. One respondent did accept "it could be used for this... if it didn't seem so gimmicky!" Where Facebook was not used by librarians, the reasons varied. One respondent felt that "it's their space, not the library's. Pretty much every library generated page only has librarians as members, which isn't really the point," whereas another "did a small survey with student representatives and they weren't interested in the Library being on Facebook." Another was "not sure it's an appropriate tool for library purposes," and for another the "advantages [are] unclear." These views are acknowledged in the literature, but the evidence suggests that increasingly only a minority of students like to keep their personal and academic space apart, (Committee of Inquiry into the Changing Learner Experience, 2009; Minocha, 2009). The following student comment from the latest research findings gives weight to this "We set it [a Facebook group] up for our group ... we added our anatomy tutor so we can ask him any questions," (Committee of Inquiry into the Changing Learner Experience). The issue of staff capacity to create and maintain the site was also a factor behind not having a Facebook site.

Two respondents got round the tension of being on Facebook but not having to be the students' "friend," by creating or using tools which could be loaded up into individuals Facebook pages, with the University of Sheffield initially creating an RSS feed application (see: http://www.librarydevelopment. group.shef.ac.uk/blogs/med dent/?p=203), which has since been replaced by a fan page for the blog. This includes an RSS feed of the posts. Swansea School of Health Science inform students on how to import a blog feed into the Notes 
application on their Facebook profile (see: http://sushslibrary. wordpress.com/2008/09/09/do-you-use-Facebook/). This approach is supported by the research carried out by Connell (2009) into students' thoughts on librarians in Facebook.

Twitter

The latest of the three technologies investigated, Twitter is the least extensively used by UK Medical School Librarians. Four libraries used Twitter, but none of these were specifically directed at medical students and, like the Facebook sites, the Twitter feeds were produced by the University Library rather than specifically the Faculty Librarians. Both the University of Sheffield Library and Cambridge University Library are using Twitter for customer service announcements such as opening hours, news items, and electronic services status updates. Cambridge Medical Library blog updates are also being fed into the University Library Twitter feed.

One respondent reported the successful use of Twitter by a lecturer as part of a biology curriculum, and that it had been used with less success with medical students the previous year (poor take up was put down to the fact that it was not compulsory). The use of other Web 2.0 resources (e.g., delicious and flickr) was also encouraged. The drive behind the use of Twitter was the individual enthusiasm of the lecturer involved, and was not because of an University or even department-wide initiative. There was doubt about the extent to which the use of Twitter by students was continued much beyond the requirements of this course however-"the students will use them if you force them into it."

Several respondents said they used Twitter on a personal/ professional basis themselves, but most comments were along the lines of "Not yet convinced it's an especially good communication tool," "Don't know much about it yet!," and "Just haven't got to grips with it and feel I won't have time to keep up with it." The feeling was that it is just too early in its development to be taken on as a standard route of communication, and some doubts were expressed as to whether the students were really using it themselves-"they have such intensive courses, and often work in groups - they see each other all day every day, why would they Twitter?"

Yet the evidence suggests that the vast majority of our students do indeed Twitter (or use another social networking site), (Committee of Inquiry into the Changing Learner Experience, 2009; Minocha, 2009). The issue of staff capacity to implement this new means of communication and keep up a flow of news, through it was a common theme and indeed the time consuming nature of planning launching and maintaining a social networking site, is a concern voiced in the literature (Minocha, 2009).

Some respondents also raised doubts about the relevance of Twitter to library services. However, most respondents were not closed to the possibility of using this in the future.

\section{Discussion}

At present, the majority of library/ medical student communication 
in the UK is still achieved via "traditional" means: Email, posts on the VLE notice-boards, face-to-face, or via student groups or academic committees with student representation. This is also true for the majority of information literacy teaching. Only a few UK Medical School Librarians are currently using Web 2.0 technologies, and this is largely experimental at the moment so there is insufficient evidence available to answer whether traditional communication mechanisms are outmoded or not. This is despite evidence that can be observed strolling through most university $\mathrm{PC}$ labs or information commons where it is obvious that Web 2.0 is very popular. Research shows that the digital generation students want their education to be interesting and they want their education to be fun. They also expect to be able to talk back (Minocha, 2009). The current generation of medical students have not grown up with Web 2.0 technologies and are largely experimenting with it as a social rather than academic tool at the moment. However, $75 \%$ of $11-15$ year olds are using social networking sites and the next generation of university students will have no memory of a pre-Web 2.0 world. As a consequence, they are predicted to be less accepting of a non-collaborative, hierarchical higher education system. As Web 2.0 evolves into a technology to support academia, so too will student familiarity. It is the older generation of academic staff (including librarians) who are likely to be less accepting of this change. This generation is predicted to lack the necessary technological skills but will need to be responsive to the idea of learning from their students (Committee of Inquiry into the Changing Learner Experience, 2009).

\section{Conclusions}

This research aimed to gain a picture of what Web 2.0 technologies are currently being used by Medical School Librarians in the UK. Only a minority of UK librarians are using Web 2.0 technologies to communicate with medical students. Sometimes these are used to push information, rather than to facilitate two way communication.

In some cases, feedback is sought, but has not been forthcoming, perhaps because students are still hesitant to post information in a public arena. There is evidence that with the use of appropriate marketing strategies, Web 2.0 technologies can generate two way communications and that this can genuinely make the library service more student driven, more immediate and more responsive to medical student needs. Further investigation is needed to review how medical student perceive this. As Minocha (2009) asserts "constant monitoring of the students experiences and timely interventions play a significant role in the success of the initiative" (55).

\section{References}

Committee of Inquiry into the Changing Learner Experience. Higher Education in a Web 2.0 World. London: JISC, 2009. Print.

Connell, R. S. "Academic Libraries, Facebook and MySpace, and Student Outreach: A Survey of Student Opinion." Portal: Libraries and the Academy 9.1 (2009): 25-36. Print. Farkas, M. "Our New Website is a Blog: Using Wordpress for Content Management." American Libraries 39.9 (2008): 45. Print. 
Hendrix, D., D. Chiarella, L. Hasman, S. Murphy, and M. L. Zafron. "Use of Facebook in Academic Health Sciences Libraries." Journal of the Medical Library Association 97 (2009): 44-47. Print.

Kamel Boulos,M. N., and S.Wheelert. "The emergingWeb 2.0 social software: an enabling suite of sociable technologies in health and health care education."

Health Information and Libraries Journal 24 (2007): 2-23. Print.

Minocha, S. A Study on the Effective Use of Social Software by Further And Higher Education

in the UK to Support Student Learning and Engagement. London: JISC, 2009.

Print.

Rushe, D. "A little bird told us these men are the cleverest Twits in the world." The Sunday Times Magazine May 20 (2009): 20-25. Print.

Savers, Michael P. Blogging and RSS: A Librarians Guide. Medford, NJ: Information Today, Inc, 2006. Print.

Sodt, J. M., and T. P. Summey. "Beyond the Library's Walls: Using Library 2.0

Tools to Reach Out to All Users." Journal of Library Administration 49 (2009):

97-109. Print.

Wood, Diana F. "ABC of Learning and Teaching in Medicine: Problem Based Learning." British Medical Journal 326 (2003): 328-330. Web. http://www.bmj.com/cgi/content/extract/326/7384/328 